\title{
A study of the reciprocating-sliding wear performance of plasma surface treated titanium alloy
}

\author{
G. Cassar ${ }^{\mathrm{a}, *}$, J.C. Avelar-Batista Wilson ${ }^{\mathrm{b}}$, S. Banfield ${ }^{\mathrm{a}, \mathrm{b}}$, J. Housden $^{\mathrm{b}}$, A. Matthews ${ }^{\mathrm{a}}$, A. Leyland ${ }^{\mathrm{a}}$ \\ a Department of Engineering Materials, University of Sheffield, Sir Robert Hadfield Building, Mappin St., Sheffield S1 3JD, UK \\ b Tecvac Ltd, Buckingway Business Park, Swavesey, Cambridge CB24 4UG, UK
}

\section{A R T I C L E I N F O}

\section{Article history:}

Received 14 May 2009

Received in revised form 3 March 2010

Accepted 10 March 2010

Available online 18 March 2010

\section{Keywords:}

Reciprocating-sliding wear

Triode plasma diffusion

PVD

\begin{abstract}
A B S T R A C T
Triode plasma nitriding was used in conjunction with electron-beam plasma-assisted physical vapour deposition of TiN and CrAlN to enhance the wear resistance of Ti-6Al-4V titanium alloy. Linear reciprocating-sliding ball-on-plate wear tests were performed to assess the tribological performance of the treated alloy. Wear volumes were correlated to changes in coefficient of friction, which is often indicative of breakdown of the surface treatment. Debris generated during wear testing was characterised using scanning electron microscopy (SEM), energy-dispersive X-ray spectroscopy (EDX), X-ray diffraction (XRD) and laser diffraction for particle size analysis. Surface micro-profilometry and SEM were used to characterise the wear scars. The results obtained indicate that, in order to assess the relative improvement in wear behaviour attained by using surface treatments it is insufficient to compare linear wear rates alone. A clear comparison is only possible if testing is carried out in steps of increasing sliding distance, until the treated/deposited layers have been completely removed. Also, it is shown that the number of repeated tests necessary to evaluate clearly the treatment and/or coating can vary substantially, depending on the observed test progression; typically this necessitates the greatest number of repeats around the point of wear at which the ball counterface contact area is in transition from the treatment layer(s) to the substrate bulk. The inherent variability in wear performance under linear ballon-plate reciprocating-sliding is correlated to debris generation, changes in relative humidity - and the resultant wear mechanisms involved.
\end{abstract}

(C) 2010 Elsevier B.V. All rights reserved.

\section{Introduction}

Surface engineering technologies are increasingly seen as being key to enable the use of titanium in applications traditionally not compatible with the material characteristics. As such, there is a growing need for techniques which are capable of providing reliable information regarding the performance of thermochemically treated and/or coated alloys. In this respect, the use of accelerated wear tests, particularly on laboratory test machinery, is extremely popular within the surface engineering research community. Different tests can be used to evaluate the tribological behaviour of newly developed surface treatments and coatings and, more mundanely, for quality control purposes. The level of success of novel tribological coatings and treatments is often assessed by one or more of the following techniques: pin-on-disc, rubber-wheel abrasion, block-on-ring, micro-abrasion (free and fixed ball), ballon-plate impact and reciprocating-sliding wear tests [1].

\footnotetext{
* Corresponding author. Tel.: +356 2340 2140; fax: +356 21343577.

E-mail address: glenn.cassar@um.edu.mt (G. Cassar).
}

Many of the available test devices and methodologies are described in standards such as ISO, DIN or ASTM. However, most of these techniques owe their origin primarily to the characterisation of bulk materials with relatively uniform hardness and elastic properties and may therefore be less applicable to functionally graded and surface-engineered materials, particularly in the case of materials with intrinsically poor tribo-mechanical properties.

The work outlined here focuses on important test parameter combinations that should be considered when using reciprocatingsliding wear data, to ascertain the capabilities of a particular surface engineering technique; this is vital in gaining a proper understanding of duplex and hybrid treatment behaviour. Such understanding is of particular relevance for treatments on substrate materials with intrinsically poor wear resistance and low elastic modulus, such as the light alloys. Following surface treatment these materials may show no signs of wear for extended periods of testing; however, under slightly changed testing conditions, exhibit dramatic changes in prevailing wear mechanisms which, in turn, can lead to rapid surface degradation and unexpected high wear.

This paper examines results obtained from ball-on-plate linear reciprocating-sliding wear tests performed on Ti-6Al-4V titanium alloy samples. The samples were surface treated using 'duplex' and 
'non-duplex' plasma-assisted processes, resulting in surfaces with varying chemical and mechanical depth profiles. The capability of nitriding treatments to provide enhanced load-bearing capacity is studied. The mechanical support provided to the deposited hard coating layer by a pre-hardened case is considered essential to avoid premature coating failure - particularly by delamination due to excessive substrate deformation.

\section{Experimental details}

A Ti-6Al-4V alloy (5.5-6.75 wt.\% Al, 3.5-4.5 wt.\% V, balance Ti) substrate was diffusion treated by plasma nitriding in a modified Tecvac IP70L commercial coating system, using a low-pressure D.C. triode configuration [2,3] and additional radiative heating. The grounded chamber served as an anode for the discharge while the samples together with the holding fixtures were the principal cathode. Thermionic plasma-enhancement was provided by an additional electron-emitting cathode in the form of a hot tungsten filament (biased at $-200 \mathrm{~V}$ ) positioned near the base of the chamber. The test coupons used ( $\varnothing 30 \mathrm{~mm} \times 3 \mathrm{~mm}$ discs $)$ had a core hardness of $375 \pm 10 \mathrm{Hk}_{0.025}$ and were polished to a mirror finish $\left(R_{a}=0.025 \pm 0.005 \mu \mathrm{m}\right)$. All triode plasma diffusion treatments were carried out for $4 \mathrm{~h}$ in a mixture of $70 \%$ partial pressure of nitrogen and $30 \%$ partial pressure of argon, at a total gas pressure of $0.4 \mathrm{~Pa}$. Further details on the triode plasma nitriding (TPN) processing of Ti-6Al-4V can be found elsewhere [4]. Selected samples were also coated with either TiN or CrAlN. The coatings were deposited by electron-beam plasma-assisted physical vapour deposition (PAPVD) using a Tecvac IP70 coater for TiN and a Tecvac IP35 coater for CrAlN. Both coatings were deposited at (bulk) substrate temperatures ranging between 400 and $450^{\circ} \mathrm{C}$. Also, for both coatings, samples were first sputter cleaned, then a thin metallic interlayer (0.1-0.2 $\mu \mathrm{m}$ ) was deposited ( $\mathrm{Ti}$ in the case of TiN and $\mathrm{Cr}$ for $\mathrm{CrAlN}$ ); finally the ceramic coating layer was deposited for approximately $100 \mathrm{~min}$, to give a thickness of typically $2-3 \mu \mathrm{m}$. The two coatings were selected based on the following criteria: (i) TiN is widely used in industry; (ii) the performance of TiN on titanium alloys has already been studied widely under both duplex and non-duplex treatment conditions [5-11]; and (iii) CrAlN is emerging rapidly as a superior ceramic film for wear protection in a variety of applications [12-15]. The thickness of the PVD coatings tested in this work was $2.8 \pm 0.2 \mu \mathrm{m}$ in the case of TiN, and $2.0 \pm 0.2 \mu \mathrm{m}$ for CrAlN.

The results presented include those related to the following samples: (a) triode plasma nitrided samples treated at two different bias voltages; a relatively low voltage of $-200 \mathrm{~V}$ (referred to as $\mathrm{LV}$ ) and a higher voltage of $-1000 \mathrm{~V}$ (referred to as HV); (b) duplex TiN and CrAlN deposited on LV samples (referred to as D-TiN and DCrAlN, respectively), and (c) TiN and CrAlN deposited on untreated substrate alloy.

\subsection{Wear experiments and characterisation}

Wear tests were performed using a low-frequency reciprocating-sliding tribometer, connected to a computer monitoring the dynamic coefficient of friction (in both sliding directions), relative humidity and temperature. Tests were performed by applying a normal load of $4 \pm 0.1 \mathrm{~N}$ or $13.5 \pm 0.1 \mathrm{~N}$ to a stationary ball of diameter $10 \mathrm{~mm}$. The ball materials used were WC-Co (5-7 wt.\%) and single crystal $\mathrm{Al}_{2} \mathrm{O}_{3}$ (sapphire). Although the latter is not common in engineering applications, sapphire was chosen due to its relative chemical inertness while also providing a necessary superior resistance to wear damage - particularly to facilitate testing to failure of CrAlN coated samples.

The ball-on-plate machine was set to run at $5 \mathrm{~Hz}$ with a reciprocation amplitude of $10 \mathrm{~mm}$ and without lubrication. The tests were performed at temperatures between 20 and $25^{\circ} \mathrm{C}$ and a relative humidity (RH) between 10 and 20\% (unless otherwise indicated). Before each test, both the sample and the ball counterface were ultrasonically cleaned in acetone for $10 \mathrm{~min}$, rinsed in isopropanol and finally dried in a jet of hot air.

After the wear tests, the morphology of each wear scar was observed by optical microscopy (OM) and scanning electron microscopy (SEM); 2D and 3D surface profilometry was performed using a Veeco Dektak $3^{\text {ST }}$ surface profilometer. The $12.5 \mu \mathrm{m}$ radius stylus tip was loaded with a force of $30 \mathrm{mg}$ and the scan duration was set such that the traversing resolution was better than $0.05 \mu \mathrm{m}$. The vertical resolution was less than $0.005 \mu \mathrm{m}$ and for a lateral resolution (along the wear scar major axis) of $25 \mu \mathrm{m}$ in 3D mapping mode. Also, for selected runs the damaged ball surface was scanned.

In order to account for effects induced by minor changes in relative humidity, within the range specified above, two other sets of reciprocating tests were devised. For the first experiment a duplex nitrided and TiN coated sample was tested at a constant $10 \% \mathrm{RH}$. For the second experiment the humidity inside the testing chamber was increased to around $80 \% \mathrm{RH}$ at the start of the test. This was left to drop naturally and again increased to $80 \%$ RH every $\sim 100 \mathrm{~m}$ until the test was finished.

In order to investigate the tribochemical products generated during testing, the debris was collected at the end of the tests. A laser diffraction particle size analyser (Beckman Coulter LS 130) equipped with polarization intensity differential scanning (PIDS), capable of measuring particles down to $0.04 \mu \mathrm{m}$, was used to obtain information regarding the size of the debris collected. Also, SEM and energy-dispersive X-ray spectroscopy (EDX) was used to obtain information regarding the morphology and chemical composition of the wear debris. Finally, the debris phase composition was studied using glancing-angle X-ray diffraction (GAXRD). A Siemens D5000 diffractometer ( $\mathrm{Cu} \mathrm{K} \mathrm{K}_{\alpha}$ radiation) was operated in Seeman-Bohlin geometry at a $6^{\circ}$ grazing angle with step size of $0.02^{\circ}$, and a step time of $3 \mathrm{~s}$ in the $30-80^{\circ} 2 \theta$ range. The tube acceleration voltage and current used were of $40 \mathrm{kV}$ and $30 \mathrm{~mA}$, respectively.

Knoop cross-sectional microhardness measurements were performed using a Mitutoyo HM microhardness tester, set at a load of $25 \mathrm{gf}$ and a 20 s dwell time; while surface nanoindentation measurements were performed using a Hysitron Inc. Triboscope ${ }^{\mathrm{TM}}$ equipped with a Berkovich triangular-pyramidal diamond indenter with an approximate average radius of curvature of $150 \mathrm{~nm}$. Fifteen indentations were made for each sample at a constant maximum indentation depth of $\sim 100 \mathrm{~nm}$ for coating measurement and $\sim 50 \mathrm{~nm}$ for nitrided samples. Corresponding maximum loads of around 10 and $5 \mathrm{mN}$ were used for coatings and nitrided samples, respectively.

\section{Results and discussion}

Hardness-depth profiles (Fig. 1a, b and c) indicate the effect of different treatment combinations, while Fig. 1d shows the bulk hardness of the counterface materials and substrate Ti-alloy. In order to give an accurate illustration of the hardness profile of each sample and particularly considering the thin nature of the coatings and nitride compound layer alike, it was necessary to measure the surface hardness using nanoindentation. This allowed the determination of local hardness without any substrate contribution to the results. For consistency, Knoop cross-sectional hardness values have also been converted to GPa.

\subsection{Wear and friction behaviour}

Data obtained from ball-on-plate reciprocating-sliding, pin-ondisc unidirectional sliding, disc-on-disc (or similar wear tests), is 

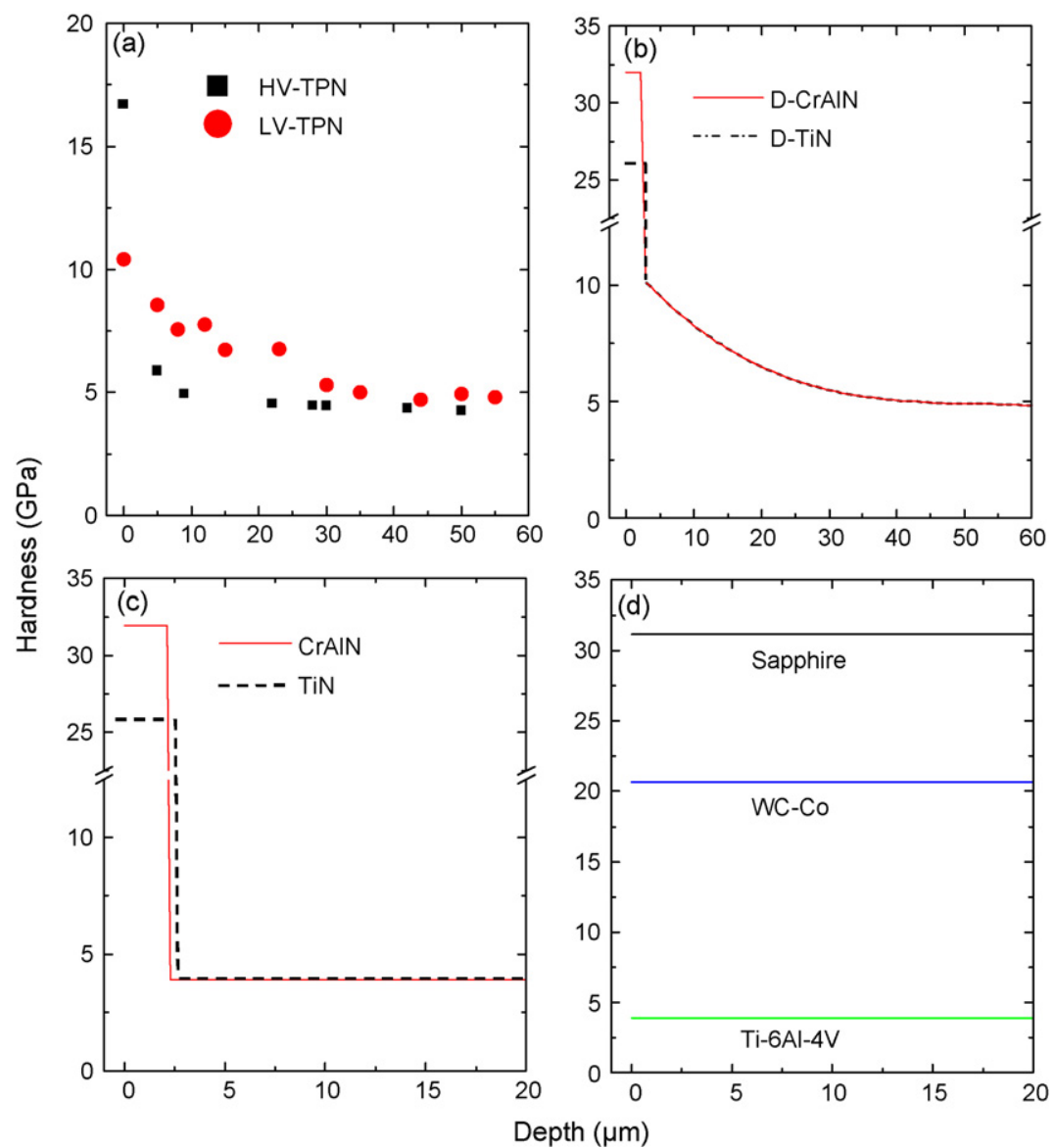

Fig. 1. (a), (b) and (c) Hardness-depth profiles for selected samples, and (d) hardness of untreated Ti-6Al-4V and the two counterface materials chosen.

most commonly presented as wear volume removed after a predetermined sliding distance or time. A comparison of HV- and LV-TPN wear data is useful to demonstrate how this assessment does not necessarily reveal the full details in regard to the performance of the diffusion-treated samples. Testing HV-TPN at $1 \mathrm{~N}$ against WC-Co shows a wear rate (calculated over $200 \mathrm{~m}$ of sliding) of $0.30 \times 10^{-6} \mathrm{~mm}^{3}(\mathrm{~N} \mathrm{~m})^{-1}$, while LV-TPN shows a marginally higher wear rate of $0.38 \times 10^{-6} \mathrm{~mm}^{3}(\mathrm{~N} \mathrm{~m})^{-1}$. It is believed that at this load the contact between the sliding counterface and treated substrate is confined to interaction between asperities and thus the nitrided case of HV-TPN was capable of supporting the ball counterface, independent of the condition of the material underneath. In this case, the harder and thicker $(\sim 1.45 \mu \mathrm{m})$, mainly TiN, surface 'compound' layer (compared to mostly $\mathrm{Ti}_{2} \mathrm{~N}$ in LV-TPN) wears slowly until the compound layer is worn through and the underlying substrate exposed. Comparatively, in LV-TPN the thinner $(\sim 0.25 \mu \mathrm{m})$ and relatively softer nitride layer wears through in a significantly shorter time. Although, in both samples, the substrate material below the compound layer is appreciably hardened (both by nitrogen in solid solution and by $\mathrm{Ti}_{2} \mathrm{~N}$ precipitates) it is not capable of reducing wear as it is tribochemically still very similar to untreated Ti-alloy.

However, in this work the authors were interested in observing the performance of the TPN treated Ti under relatively high contact pressures, approaching the yield strength of the base metal, $\sim 830 \mathrm{MPa}$ [16]. Subsequent testing at higher loads shows a different behaviour. Fig. 2a shows the wear volume measured after test runs for different sliding distances at $4 \mathrm{~N}$ against a WC-Co counterface. At higher normal loads the substrate of HV-TPN is not able to support the hard (and elastically stiff) compound layer at the sur-

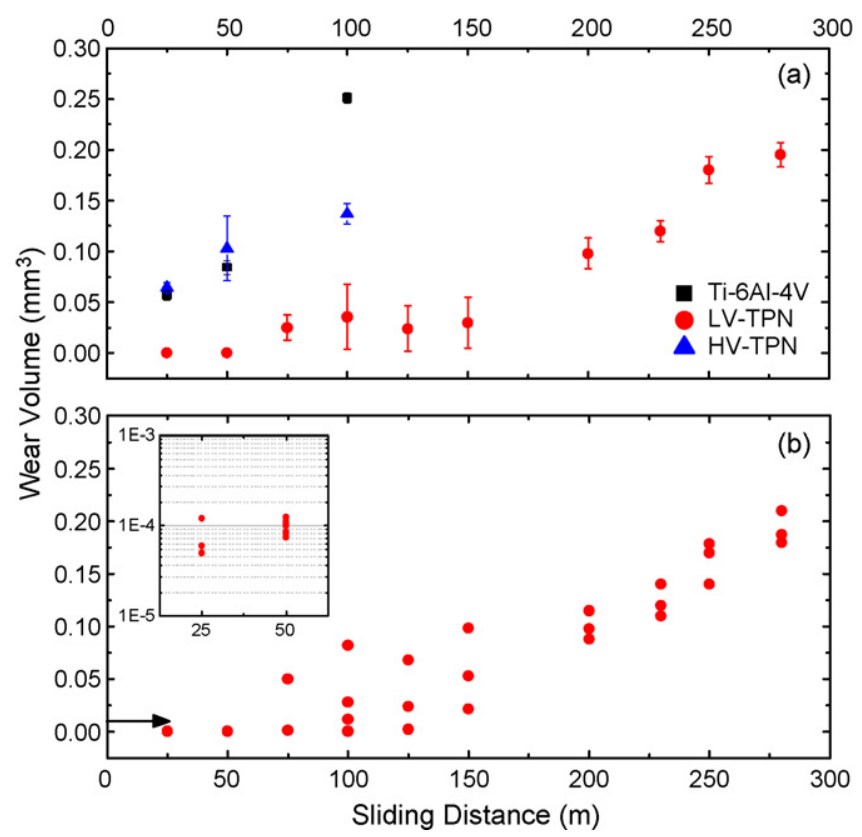

Fig. 2. (a) Wear volume measured for Ti-6Al-4V, LV-TPN and HV-TPN tested against a WC-Co ball counterface at $4 \mathrm{~N}$ load for different sliding distances. (b) The complete set of data generated for LV-TPN. The arrow on left hand side represents (approximately) the wear volume equivalent to a scar depth of $2 \mu \mathrm{m}$. 




Fig. 3. Friction coefficient evolution for several LV-TPN test runs and HV-TPN under $4 \mathrm{~N}$ load, sliding against a WC-Co ball counterface.

face. The resulting substrate plastic deformation causes premature cracking in the surface, leading to very rapid failure. The importance of the mechanically supporting diffusion layer (despite its relatively poor tribological performance in isolation), particularly at higher loads, is evident [17].

It is instructive to examine more closely the data used to generate the plot for LV-TPN in Fig. 2a. Fig. 2b shows the entire set of data points generated on notionally identical LV-TPN samples. The latter plot shows how, for testing distances above $75 \mathrm{~m}$, there exists a larger scatter in measured wear volumes, which seems then to stabilise above $150 \mathrm{~m}$. This variation depends on the exact moment when the hard, wear-resistant nitride compound layer present on these samples is removed and accelerated substrate wear commences. The inset in Fig. 2b clearly shows that the wear rate measured for the early stages of the test is very predictable with volumes almost identical from run to run. The sudden transition to higher wear rate is accompanied by a change in coefficient of friction (CoF). Fig. 3 shows the corresponding CoF data for multiple tests on LV-TPN and HV-TPN samples. For LV-TPN the friction coefficient is not constant during the test. An initial running-in period, during which the CoF is rising, can be observed. This is followed by a steady-state region which varies from test to test, from a minimum of $\sim 60 \mathrm{~m}$ of the total sliding distance during run 1 up to a maximum of $\sim 110 \mathrm{~m}$ of the total sliding distance during run 4 . At the point of 'failure' the CoF, originally in the range of 0.8-0.9, falls rapidly to around 0.45 . This represents the instance when the compound layer has been worn through and the ball makes contact with the underlying $\mathrm{N}$-hardened substrate. Following this drop, equivalent to Ti sliding against transferred Ti [18], larger fluctuations are also noticeable in the CoF. These have been correlated principally with the presence of third body particles, the adhesion between metallic titanium regions and differences between the static and kinetic friction coefficients creating stick-slip behaviour between the asperities [9,19].

The almost instantaneous change in CoF between nitride and bulk values suggests that the compound layer is only partially worn at the point of failure, but any remaining layer is immediately stripped off the substrate. Considering that applied contact pressures are in the region of the yield strength of the material it is perhaps not surprising that plastic deformation may be induced in the region of maximum contact stress (which, at this stage, is probably at, or below the treatment/substrate interface). As the hard surface layer is worn, the remaining material is unable to withstand the flexural stresses, leading to failure. The detected variance when this happens seems to correlate with the CoF behaviour dur- ing the running-in period. A more gradual rise in $\mathrm{CoF}$ (particularly due to slightly reduced maxima) can have significant effects on the wear life of the surface. Comparing runs 1 and 4 in Fig. 3 shows a $200 \%$ increase in distance-to-failure of the latter. The presence and distribution of asperities creating resistance to sliding (by ploughing and adhesion) together with the generation of debris (discussed later) can be the principal variants affecting the rise in the CoF. In the latter case the early generation of debris, say from failure at minor imperfections, may create a cascade effect with more particles rapidly generated [20]. The added ploughing by particles and increasing adhesive component (due to the larger 'clean' contact area) would, at the same time, lead to higher CoF values [21]. The nature, size and distribution of these flaws could well determine for how long a surface can survive under such reciprocating-sliding wear conditions. Other factors, such as the preferential nitride growth texture observed, could also influence changes in $\mathrm{CoF}$ [22]. Different nitride lattice orientations can present different hardness values and therefore vary in their resistance to wear [23]. Effects of changes in RH will also be discussed in the following section.

In the case of HV-TPN, also shown in Fig. 3, the CoF rises immediately to around 0.45 , and is therefore identical to untreated Ti-alloy under the same testing conditions. This is in agreement with the wear volume data presented in Fig. 2, i.e. at higher loads HV-TPN does not provide any significant improvement in wear resistance. The reduction in wear experienced at higher distances is related to the test contact geometry. As the ball penetrates deeper into the substrate, the contact pressure drops rapidly and therefore the sides of the ball along the sliding direction can be marginally supported by the remaining hard nitride compound, thereby slowing the progression of wear.

The discussion above also gives a basis for understanding why LV-TPN samples outperform HV-TPN in ball-on-plate reciprocating sliding. The most evident difference between the two is the hardness-depth profile (Fig. 1). For reasons explained previously, a softer, but better supported nitride compound layer is more effective in absorbing substrate deflections. By virtue of a deeper strengthened case, spalling induced by processes such as surface fatigue can also be reduced, since the maximum shear zone (calculated at around $26.7 \mu \mathrm{m}$ in depth for a static system) is constrained within this region. However, there are also other important considerations, particularly in relation to the surface finish generated by the nitriding treatment parameters. Fig. 4 shows two-dimensional profiles of surface topography for the different treatments. HV-TPN exhibits a distinctly rougher topography, characterised by many conical asperities. This can be attributed both to the sputter-etching mechanism during processing and to the nodular growth of nitride

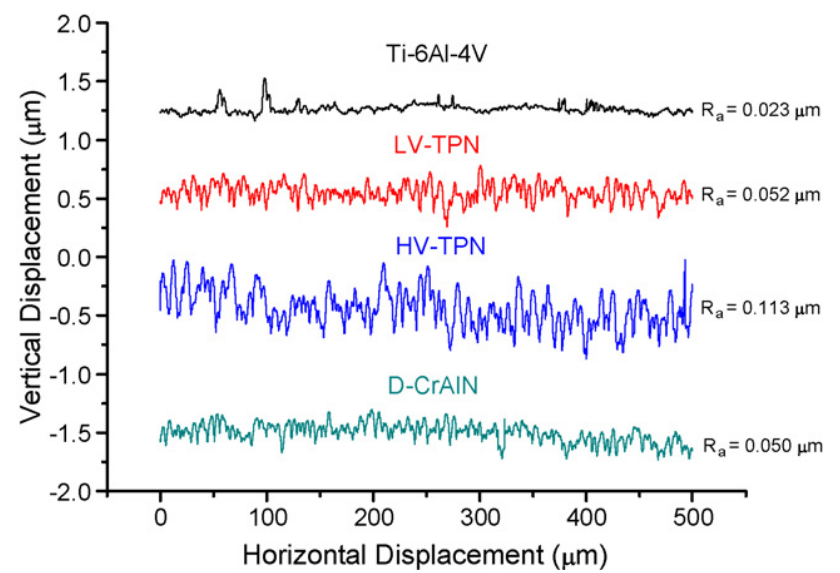

Fig. 4. Two-dimensional surface profilometry, showing roughness variations with surface engineering treatment. 


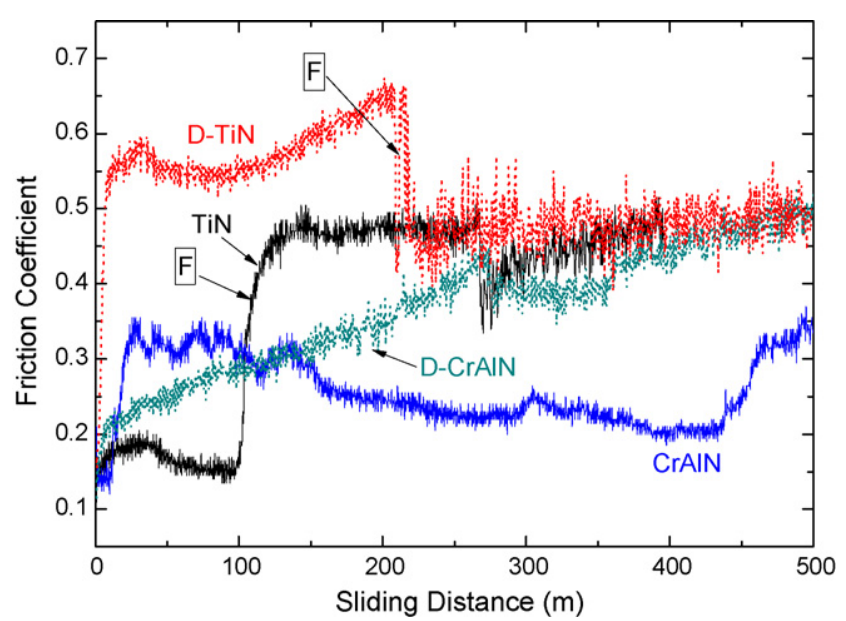

Fig. 5. CoFs for selected samples tested at $13.5 \mathrm{~N}$, ND-/D-TiN against WC-Co and ND-/D-CrAlN against sapphire. F marks the coating failure for TiN coated samples.

protuberances during the plasma diffusion treatment [24]. HV-TPN is therefore more prone to generate debris at an early stage of sliding wear, as surface asperities are rapidly work hardened and fractured by fatigue. The friction coefficient of diffusion-treated samples has often been found to increase due to the surface roughening induced during sliding wear $[8,25]$.

Similar concepts can be applied to compare duplex and nonduplex-treated samples. Fig. 5 shows the CoF of selected duplex (D) and non-duplex (ND) samples. Observation of the different CoF profiles can give insights into the behaviour of these treated surfaces. For instance, it was noticed that TiN samples may have short running distances $(<200 \mathrm{~m})$ with low CoFs of around 0.15 . This is particularly evident when testing at higher normal loads and can in part be explained by increased chemical activation of the surface, leading to tribo-oxidation [26]. Both the oxidative degeneration of TiN and the associated reduction in friction by the generation of a low shear strength nanolayer tribofilm are well documented [27-30]. Conversely, when testing D-TiN this initial running-in period at low CoF hardly ever occurs. It is likely in this case that the asperity fracture immediately introduces some debris into the system, increasing the CoF. CrAlN also presents a low CoF value; however this is always the case, suggesting that oxidation products, such as alumina, are more stable and adherent when compared to those formed on TiN. Also, unlike TiN, the CoF increases slowly to 0.45 ; proof of a more gradual coating failure. Although the failure of CrAlN is never abrupt, the rate of increase is largely accelerated when testing against a sapphire ball counterface and/or under high load. For D-CrAlN the CoF at $4 \mathrm{~N}$ load remains constant at $\sim 0.25$, with no measurable signs of wear, up to the maximum sliding distance of $3000 \mathrm{~m}$ used for this study. On the other hand, at $13.5 \mathrm{~N} \mathrm{a}$ more rapid increase in $\mathrm{CoF}$ is measured. The rate of this increase largely dictates the durability of the coating. Even higher loads further stabilise the variability in CoF during the early part of the test. It is postulated that, at sufficiently high loads, wear debris is almost instantaneously generated-leading to a very quick rise in $\mathrm{CoF}$, irrespective of the local surface condition. Similarly, this range of apparent stability is also restricted at the high load end for coated samples. Once the load is increased beyond some critical point catastrophic coating failures may occur. This was particularly evident for TiN coated coupons, which under repeated testing, exhibit slightly different rates of $\mathrm{CoF}$ increase during running-in, leading to variations in the coating life (with higher rate of increase equating to shorter life).

The changes described for the CoF are also reflected by large differences in tribological performance between samples. The

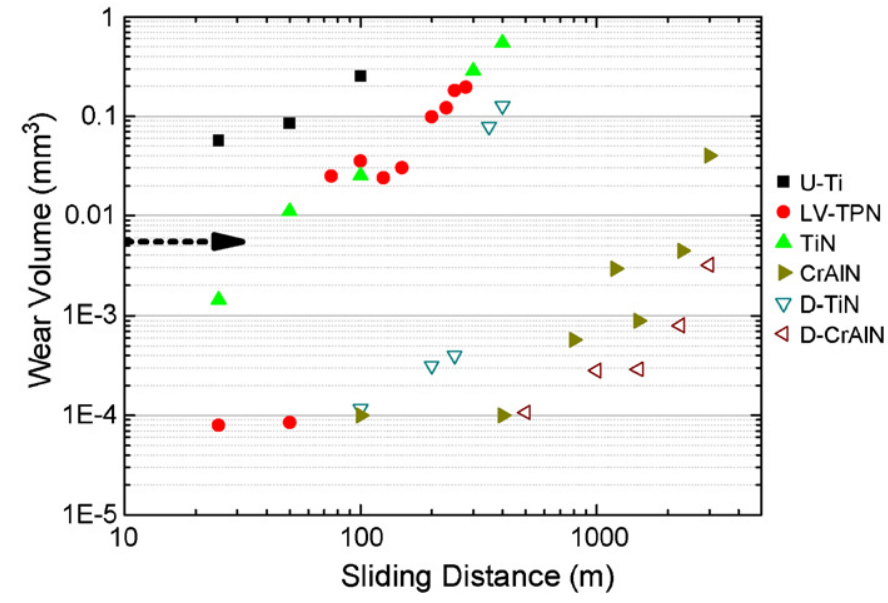

Fig. 6. Wear volumes measured for selected samples; Ti-6Al-4V and LV-TPN tested against WC-Co at $4 \mathrm{~N}$ load; TiN/CrAIN and D-TiN/CrAlN tested against WC-Co at $13.5 \mathrm{~N}$. The arrow on the left hand side represents (approximately) the wear volume equivalent to a scar depth of $2 \mu \mathrm{m}$, i.e. the ball has penetrated through the coating.

deposition of a hard compound on a suitably pre-treated substrate did, as expected, increase the wear resistance of the sample when tested under ball-on-plate reciprocating-sliding. Fig. 6 shows the wear volumes of selected samples in comparison with uncoated Ti-6Al-4V. Clearly, CrAlN nitrided samples performed best under the testing regime used in this work, particularly in comparison with TiN. The pre-nitriding process increases substantially the life of duplex-treated samples. D-CrAlN samples were tested up to a sliding distance of $3000 \mathrm{~m}$ (equivalent to over $500 \mathrm{~min}$ of testing), achieving a maximum wear depth of less than $1 \mu \mathrm{m}$. In terms of wear rates the untreated Ti-alloy tested against WC-Co at $13.5 \mathrm{~N}$ has a wear rate of $366.74 \times 10^{-6} \mathrm{~mm}^{3}(\mathrm{~N} \mathrm{~m})^{-1}$ (based on a $50 \mathrm{~m}$ test) while, under the same conditions, D-CrAlN has a wear rate of $0.08 \times 10^{-6} \mathrm{~mm}^{3}(\mathrm{~N} \mathrm{~m})^{-1}$ (based on a $3000 \mathrm{~m}$ test) before coating failure.

However, the improvement in resistance to wear is most importantly also accompanied by a reduction in performance variability, as described earlier. A series of tests on notionally identical CrAlN and D-CrAlN samples were carried out. Each sample was repeatedly tested over increasing sliding distances, using $13.5 \mathrm{~N}$ load, against a sapphire ball counterface. Fig. 7 shows the sliding distance at which coating failure is first observed (i.e. where the measured maximum wear scar depth exceeded $2 \mu \mathrm{m}$ ). Not only is the nominal sample durability higher for the duplex-treated coupons, but the variability of the coating response to such aggressive wear condi-

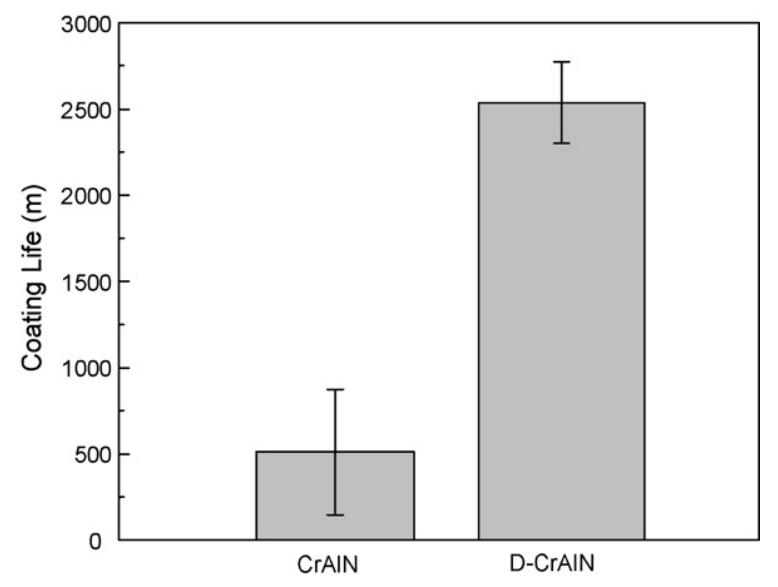

Fig. 7. Sliding distances survived by non-duplex and duplex CrAlN coating tested under $13.5 \mathrm{~N}$ load, running against a sapphire ball. 
tions is also substantially reduced. The coefficient of variation (i.e. the ratio of the standard deviation to the mean 'failure' distance), is in fact greatly diminished for D-CrAlN when compared to CrAlN alone, from $>0.7$ to $<0.1$. The load support offered by the nitriding process inhibits catastrophic modes of failure, such as delamination and damage initiation/propagation due to plastic deformation of the substrate. Such knowledge regarding the reliability of surface treated components can allow a more precise prediction of product life during the early design and development stages, and ultimately permits the use of treated products for more demanding requirements, closer to the intrinsic limit of the coating/treatment capabilities.

If the generation of wear debris is indeed a principal factor for the rising CoF during reciprocating ball-on-plate sliding, it is plausible to expect that once this cause is removed the CoF should maintain a lower value - at least until further debris is created in the system. We therefore devised a sliding experiment to examine the effect of particle removal in PVD layers and nitride compounds. D-TiN and LV-TPN were in this case tested against a WC-Co ball counterface (although different loads were used for duplex and non-duplex samples). For D-TiN the test was stopped at $150 \mathrm{~m}$ and the debris was removed using a powerful jet of dry air, while for LVTPN this procedure was repeated twice, at around $50 \mathrm{~m}$ and again at $150 \mathrm{~m}$. Fig. 8 shows the CoF measured during these tests. For the conditions selected, the CoF rises immediately for both samples up to point 1 . At this point the run was interrupted and the debris removed. Once the test was resumed, the CoF remained below 0.2 for a considerable sliding distance. This period of low friction behaviour could not be measured at the start of the test irrespective of whether debris was present or not. This shows that, once the surface asperities have been 'lapped' off, the generation of new particles is more difficult and possesses some inherent incubation period. As particles are eventually generated (point 2 in Fig. 8), the CoF then rapidly rises. For LV-TPN this cycle was repeated and, clearly, a similar drop in friction occurs again; however the running distance at low CoF is now reduced, since finally the hard surface layer is removed by abrasion and at point 3 in Fig. 8 the substrate material is exposed.

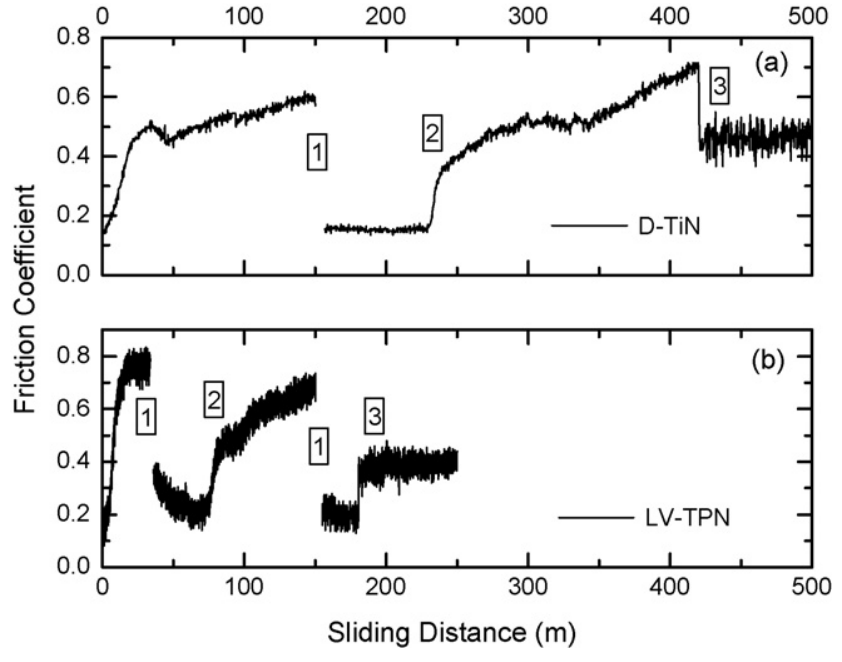

Fig. 8. Effect of wear debris removal during reciprocating ball-on-plate sliding tests; (a) D-TiN tested for $500 \mathrm{~m}$ at $13.5 \mathrm{~N}$ load, and (b) LV-TPN tested for $250 \mathrm{~m}$ at $4 \mathrm{~N}$, both against a WC-Co ball counterface.

\subsection{Analysis of wear debris}

The accumulation of wear debris during testing is obviously a major factor affecting the wear behaviour of the samples - since it can induce accelerated wear rates by changing what is essentially a two-body abrasion system into a more aggressive, three-body regime. The characterisation of such particles is particularly relevant for the understanding of reciprocating ball-on-plate sliding tests since: (i) the test operating mechanics make removal of particles from the wear track more difficult; and (ii) the high hardness and associated brittleness of both elements of the tribocouple creates a greater possibility for the introduction of hard abrading particles within the system. SEM observation of wear debris (Fig. 9a) generated by sliding uncoated Ti-6Al-4V against sapphire shows different morphologies and granule sizes of up to several
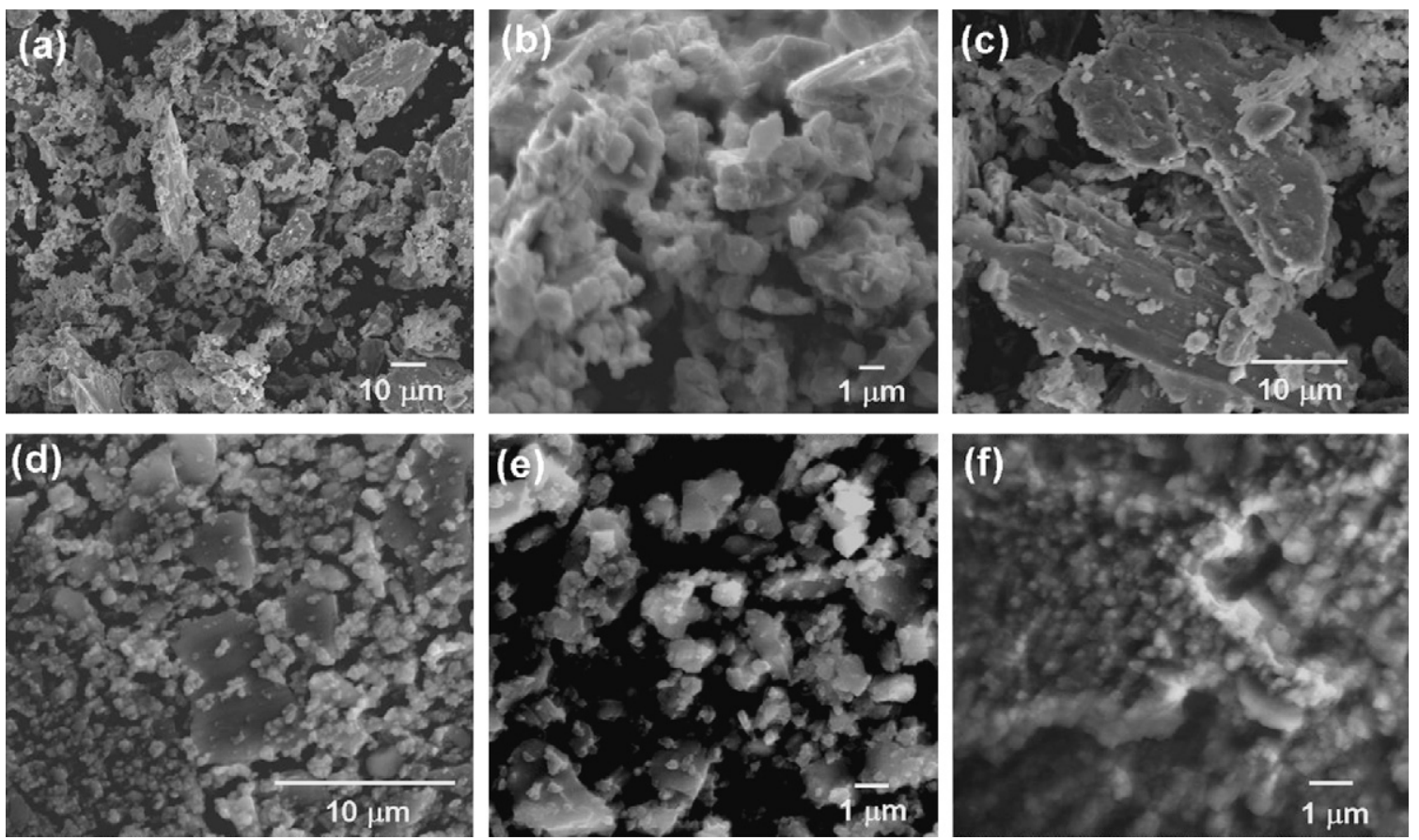

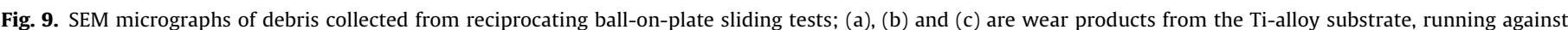
sapphire, (d) was collected from TiN against WC-Co, and (e) and (f) are from CrAlN when tested against sapphire. 
tens of microns. Fig. 9b shows that many of these granules are actually agglomerates of much smaller particles. These fine powder structures can be explained by linking of oxides with water molecules from the environment and the consequent formation of hydrated structures [31]. Also, high aspect ratio plate-like debris is also visible (Fig. 9c). This may be confused with delaminated substrate material; however careful observation of many of these particles shows that they are formed from smaller highly compacted particles, generated by the ball repeatedly traversing across the accumulated debris. These elongated particles show striations along their major axis. For a ductile metal such as Ti it is plausible that smaller particles which are not ejected from the contact path are plastically worked into large particles - although the fact that these seem to be present in only small amounts may also be related to the reciprocating nature of this test. The continuous change in sliding direction may promote early breakup and potentially make the test mechanism more aggressive by maintaining relative finer debris stock. Indeed, both these types of agglomerates have previously been reported for softer metals [20]. EDX analysis was also used to analyse the composition of the debris and clearly both type of agglomerates contained large amounts of oxygen ranging between 49 and 64 at.\%. This allowed the verification of the composition of the elongated plates. Oxygen mapping of a relatively large area $(100 \mu \mathrm{m} \times 100 \mu \mathrm{m})$ showed oxygen presence almost everywhere, excluding a few isolated platelets with a composition close to the nominal substrate values. The information gathered by particle diffraction sizing and PIDS measurements of the tribochemical products collected was integrated in order to generate the data presented in Fig. 10. Debris was found to have a mean diameter of only $1.4 \mu \mathrm{m}$ and $90 \%$ of the particles sampled were smaller than $2.7 \mu \mathrm{m}$. This confirms that the large majority of particles observed under SEM are in fact agglomerates constituted by far smaller particles which then disperse during analysis.

Similar SEM analysis was performed on D-TiN and D-CrAlN tested against WC-Co and sapphire, respectively. An important difference can be observed by comparing Fig. 9d and e, representing TiN and $\mathrm{CrAlN}$, respectively. The debris generated by TiN coating is composed of relatively few large particles (up to around $10 \mu \mathrm{m}$ in length) of coating material and for the majority smaller, multifaceted and non-agglomerated particles. Considering the size of the particles, it is plausible that these may be captured by the topography of the roughened, duplex-treated surfaces, resulting in ploughing and scratching, further accelerating the wear rate. The presence of $\mathrm{W}$ from the ball counterface was also detected. On the other hand, for CrAlN no large platelets were observed and the debris collected appears to be made of tightly pressed, very fine

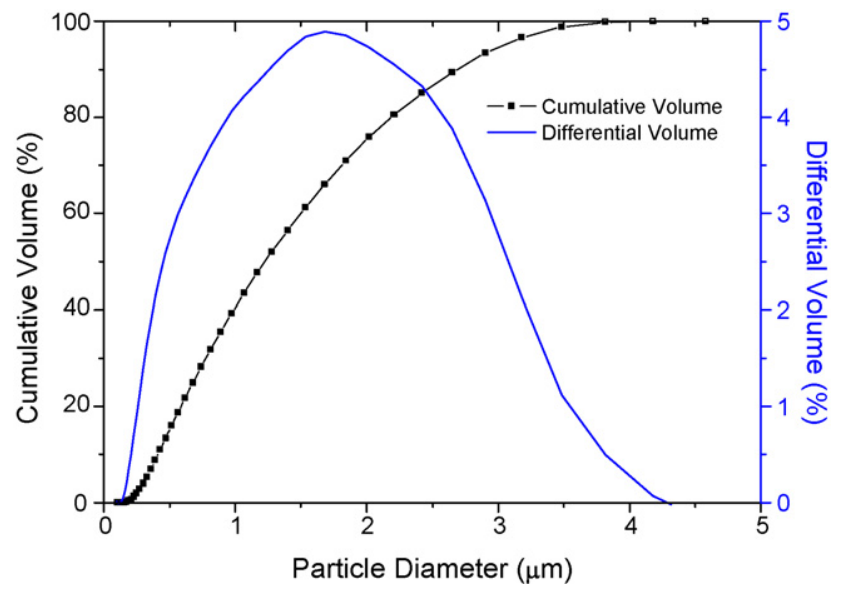

Fig. 10. Particle size distribution of wear debris generated by reciprocating-sliding ball-on-plate.
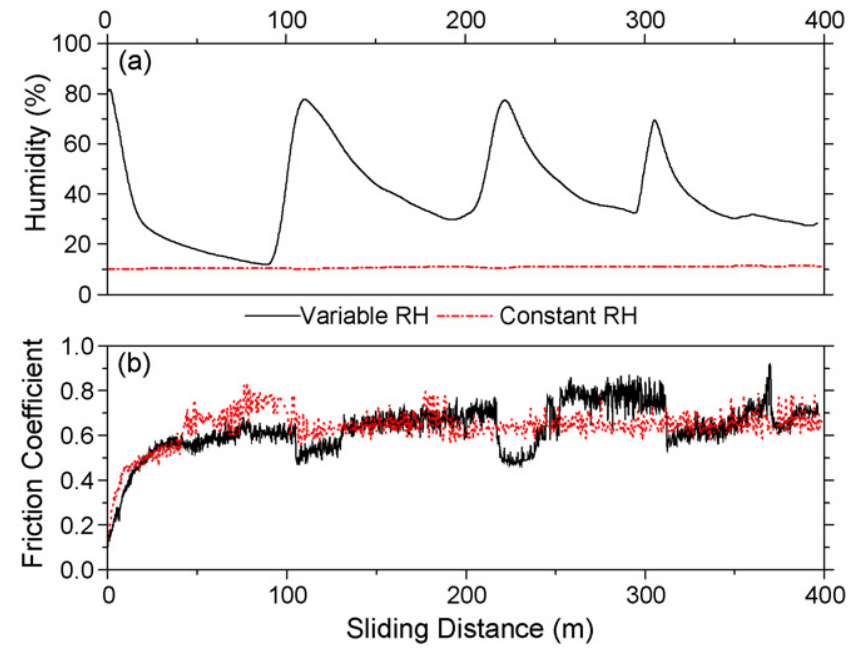

Fig. 11. Evolution of (a) relative humidity, and (b) equivalent variation in CoF during reciprocating ball-on-plate sliding of D-TiN against a sapphire ball counterface.

particles consisting of $\mathrm{O}$ (above 40 at.\%), $\mathrm{Cr}$ and $\mathrm{Al}$. The greater particle packing can be attributed to the higher testing loads used to wear CrAlN, together with a greater drive to agglomerate due to the increased surface area to volume ratio - and resultant free energy. Since practically no nitrogen presence was detected, when properly supported, both coatings seem to fail primarily by friction-induced oxidation.

GAXRD was also performed on the debris accumulated from testing D-TiN and D-CrAIN against WC-Co and sapphire. The major peaks which were clearly identifiable are consistent with $\mathrm{Al}_{2} \mathrm{O}_{3}$ and $\mathrm{Cr}_{3} \mathrm{O}$ for D-CrAlN. Although the oxidation of $\mathrm{CrAlN}$ and formation of $\mathrm{Al}_{2} \mathrm{O}_{3}$ is expected, the GAXRD work carried out used particles contaminated with substrate-generated material and therefore it is not clear whether the coating, substrate or both generated the crystalline $\mathrm{Al}_{2} \mathrm{O}_{3}$ phases observed. The formation of stable alumina on CrAlN may also assist in maintaining a low friction coefficient, and reducing oxidative and abrasive wear. The absence of well defined nitride and titanium oxide peaks, points towards amorphization during tribo-oxidation of the test sample. Sufficient literature supports the hypothesis that amorphous phases are prevalent under the wear testing conditions used, particularly at low humidity and high friction force [29,31,32]. Similar GAXRD work carried on debris collected from coated samples which had not been pre-nitrided also showed the presence of various nitrides peaks (mainly $\mathrm{CrN}$ and TiN) which are likely to be present as a result of coatings fracturing off the softer substrate. Further characterisation related to particle composition and structure is planned, particularly using Raman spectroscopy.

\subsection{Humidity effects}

Fig. 11 shows the CoF evolution and $\mathrm{RH}$ variation over the test duration for D-TiN tested at $13.5 \mathrm{~N}$ normal load against a sapphire ball counterface. When the relative humidity is periodically increased to $\sim 80 \%$, the CoF drops by around 0.2 . This change is evident at $\sim 100, \sim 200$ and $\sim 300 \mathrm{~m}$, while for the first increase in RH at $\sim 0 \mathrm{~m}$, the effect is less noticeable - since the sample is within the running-in phase, during which period the humidity levels have dropped considerably. On the other hand, for a constant $10 \% \mathrm{RH}$ the CoF is far more stable, with only relatively small fluctuations (which have been explained earlier). Alumina is known to form a lubricious tribofilm of aluminium hydroxide [33] and this can be stimulated by the higher presence of water molecules in moist air, in conjunction with thermal energy generated by friction. Also, careful observa- 
tion shows a small delay (around $5 \mathrm{~m}$, or $50 \mathrm{~s}$ ) between the rising $\mathrm{RH}$ and the point at which the CoF starts to drop. This has also been reported in previous work and it is expected that a certain period of time is required for a continuous, lubricating tribofilm to form [34]. In the same way, at low RH levels, longer times are required for the ball surface to be covered by such a film. Other constant humidity experiments, up to $45 \% \mathrm{RH}$, have been carried out (not presented here) to ascertain whether changes in RH influence significantly the wear behaviour; however no definitive direct correlation could be made between CoF and humidity. In agreement with other studies [35], any changes in CoF between tests carried out at up to $50 \% \mathrm{RH}$ were minimal, with reductions in mean CoF value below 0.1 and thus below the level of general fluctuations in CoF.

When comparing the mean CoF (Fig. 11b), between the RH peaks, a small increase in mean value can be seen. This may be caused by an increased amount of particulate debris adhering to the counterface during the high humidity period [36]. As the nature of this layer changes under dry conditions $(<50 \% \mathrm{RH})$, a more severe three-body wear component generates higher CoF values.

The general lowering in CoF at high humidity levels may suggest that a corresponding reduction in wear should be noticed. In this respect, EDX results on debris generated during this test show a higher oxygen intensity peak compared to tests run at $10 \% \mathrm{RH}$, reaffirming the tribochemical nature of the degradation of a TiN film. Hence, the reduced coefficient of friction does not directly imply a reduction in wear rate - due to the possible increase in tribo-oxidation of the coating. Similarly, the increased accumulation of wear debris on the surface of the ball described earlier, may lead to the formation of W-shaped scars (described in the following section) which can also increase wear. Although further experimentation is needed (particularly considering the intrinsic test variability described earlier), it is apparent that a test performed under variable $\mathrm{RH}$ results in a substantially larger wear track when compared to that performed at (say) a constant $10 \% \mathrm{RH}$. Indeed, the final perturbation shown in the CoF plot of Fig. 11 is likely to be related to the first stages of TiN coating failure and substrate exposure.

Finally, similar humidity experiments were conducted with sapphire on untreated Ti-6Al-4V. This tribocouple showed no particular response to changes in humidity up to $80 \% \mathrm{RH}$. The substantial wear (and corresponding generation of oxide particles), together with the expected transfer of titanium metal, are unlikely to allow the formation of any lubricating hydroxide layer on the surface of the ball and, as expected, no net difference in CoF can be detected.

\subsection{Analysis of wear tracks and ball surface}

Observing the wear tracks generated on treated samples can provide information on the wear mechanics of reciprocating ballon-plate sliding; of particular interest are the changes induced by differences in the treatment combinations. 2D surface profilometry of wear scars shows two main types; U-shaped and W-shaped. In the latter, the maximum wear depth is not at the centre of the scar but at the border of it. Single and multiple valley scar geometries have been previously reported in both reciprocating-sliding and fretting wear tests [31,37]. The change in scar profile has been attributed to the gross-slip conditions of the test and the resultant generation and distribution of debris within the contact area [36]. Material adhesion to the ball surface influences the shear zone location and Hertzian pressure distribution underneath the ball. As the zones of maximum shear move outwards from the centre of the scar, the scar profile changes from U-shaped to W-shaped.

Fig. 12 shows wear scars for different samples during the early stages of failure. The stark contrast between the wear track on the untreated Ti-alloy and those on the treated samples (both duplex and un-nitrided), clearly demonstrates a change in the mechanism of material removal from abrasive-adhesive wear to milder abra-

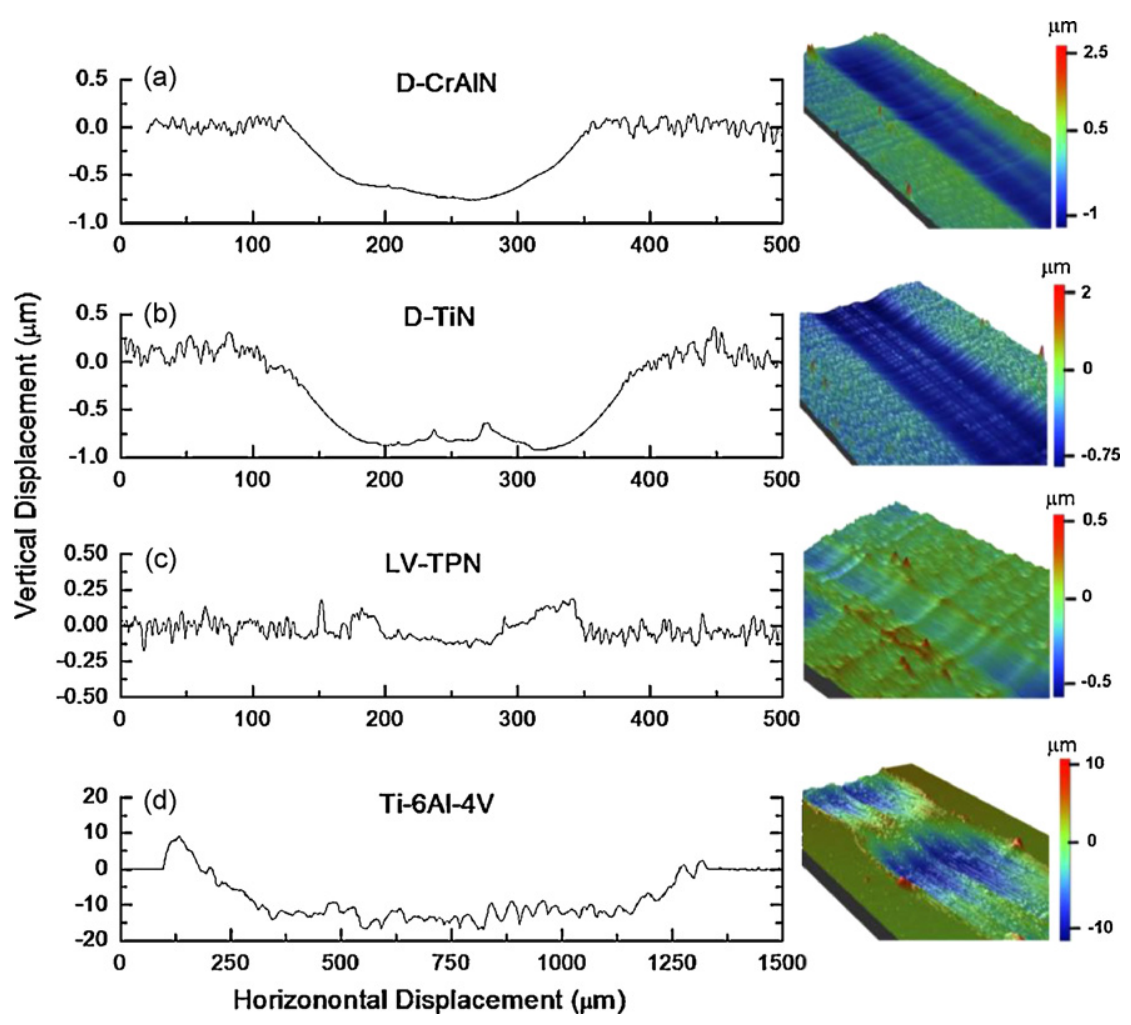

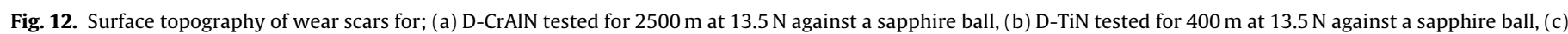
LV-TPN and (d) Ti-6Al-4V both tested for $50 \mathrm{~m}$ at $4 \mathrm{~N}$ load against a WC-Co ball counterface. 
sion for the latter [38,39]. The D-CrAlN (Fig. 12a) scar is extremely smooth with almost no detectable roughening, possibly due to a slow polishing action by the small debris particles being generated and their relative ease of removal from between the contact surfaces [40]; while the D-TiN (Fig. 12b) is slightly rougher, indicating debris entrainment. This, together with the higher ratio of hardness to (reduced) elastic modulus of CrAlN (0.103) compared to TiN (0.066), may be contributory factors to the remarkable performance of the former $[41,42]$. Fig. $12 \mathrm{~d}$ shows a typical wear scar on Ti-6Al-4V, having the characteristic features of micro- and macroadhesion. Repetitive formation and breakage of material junctions leads to relatively large protruding asperities in the scar, while the large fluctuations in wear depth along the sliding direction indicate stick-slip movement. More detailed observation of the morphology of wear scars, for non-duplex and duplex TiN coated samples (see Fig. 13) shows that the pre-nitriding process is not only beneficial when the coating is intact but also once it has been partially worn. Although the ball has perforated the coating, the trace for D-TiN coating shows that the wear is constrained to within the central region. The coating adjacent to this region is still capable of supporting the applied load - and therefore wear progresses more slowly. The test results show that coatings directly deposited on Ti-alloy are quickly removed across the entire contact area since the thinned coating region is unable to resist deformation and rapidly exfoliates. The friction behaviour and wear scar morphology have been attributed in part to adhesion of material to the ball surface. SEM and EDX analysis of a WC-Co ball, which had been used to test D-TiN (Fig. 14a), indeed showed large amounts of adhered material with composition almost identical to the Ti-alloy substrate (EDX elemental analysis: Ti 88.61 wt.\%, Al 6.04 wt.\%, V 4.53 wt.\%, W $0.81 \mathrm{wt} . \%$ ). At the centre of the contact region (Fig. 14b) the analysis mostly reveals $\mathrm{W}$, with large amounts of $\mathrm{Ti}, \mathrm{O}$ and some $\mathrm{N}$ also detected, suggesting that oxides and nitrides (from coating and TPN process) can become embedded in the counterface by the large contact pressures. As a result, once failed, hard coatings can have long

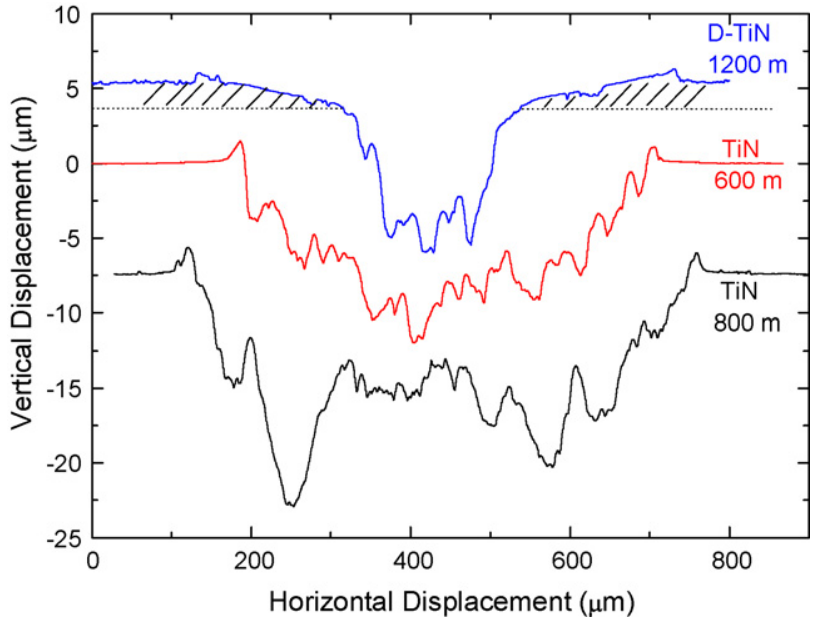

Fig. 13. Wear track profilometry scans for TiN deposited on untreated Ti-6Al-4V and a nitrided substrate, following testing at $4 \mathrm{~N}$ load against WC-Co.

lasting effects on the tribology of the system. Indeed, all nitrogencontaining layers had long been removed from the sample surface during this test run, and therefore hard coating debris was maintained in the contact area for many cycles after these layers had been worn through.

Due to the high hardness of the coatings deposited, balls used for testing were also worn. Fig. 15 shows some of the profiles measured following wear tests. Looking at the profiles presented for sapphire ball surfaces, which had been used to test D-CrAlN, it can be seen that the ball has lost a considerable amount of material. Also, the ball scar and track generated are clearly similar; however there exists a noticeable gap between the two. This space accommodates the particulate matter generated during the test. The distance between the two flattened surfaces for the $3000 \mathrm{~m}$
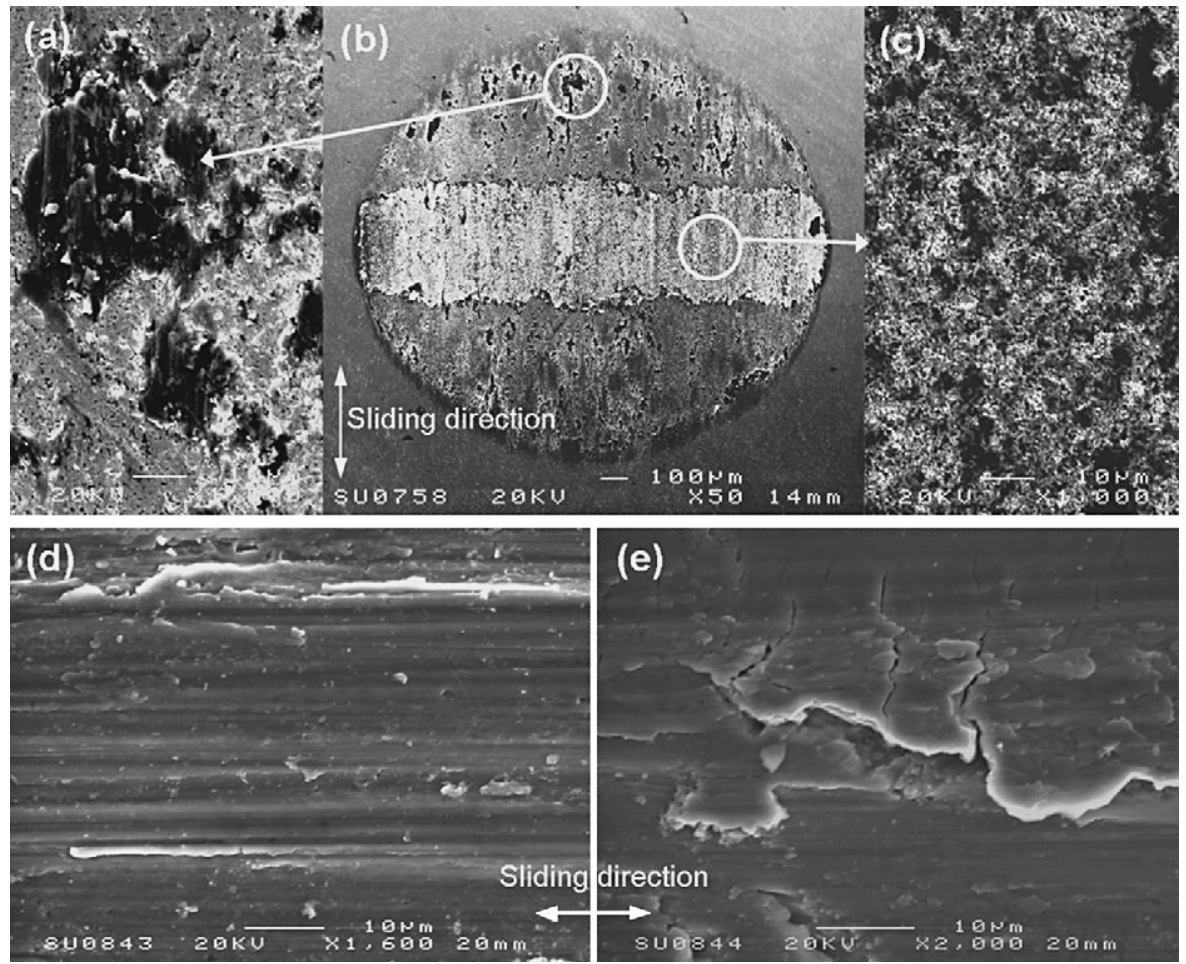

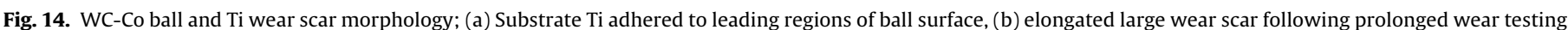
(c) roughened central region of WC-Co ball, (d) grooving marks on untreated Ti-alloy, and (e) exfoliation of the metallic substrate surface across the wear track. 


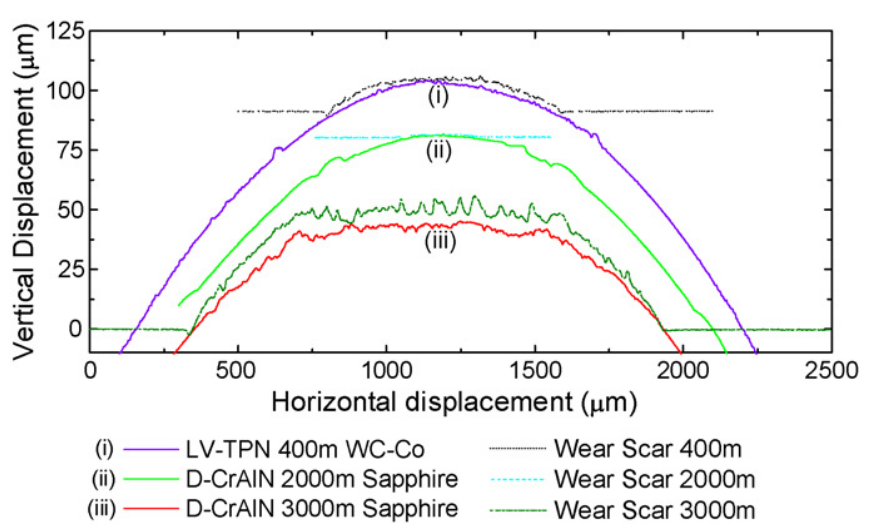

Fig. 15. Ball counterface surface wear profiles following testing against selected samples. Dotted lines represent the corresponding (inverted) wear scar generated on the treated/coated substrate.

run was measured at $3.1 \pm 0.6 \mu \mathrm{m}$ and therefore the debris is likely to be substantially embedded into the surfaces. The larger grooves found in the substrate material show that it is obviously more susceptible to damage but also that the wear peaks observable in the wear track have not been generated by asperities on the ball; substantiating the supposition that such sharp peaks in the substrate are related to grooving (Fig. 14d) generated primarily by abrasive debris trapped within the sliding couple. It was also observed that, while WC-Co may be worn down without substantially damaging the surface being tested, sapphire wears gradually in conjunction with the counterface. It is likely that the harder sapphire ball is worn by local pressure peaks generated by the debris; if the ball was wearing down at an increasing rate the contact area would increase, thereby reducing the contact pressure and in turn slowing the process and balancing its overall rate with that of the sample. Large dimples up to several microns deep are also visible on the sapphire ball surface. This form of damage may be caused by local fractures as the accumulated stresses in the hard ball surface increase sufficiently to initiate cracking and subsequent pull out of fractured particles. Finally, SEM observation of the wear scars (Fig. 14e) also shows sites potentially leading to the generation of debris through fatigue-induced cracking and delamination.

\section{Conclusions}

Triode plasma nitriding prior to the deposition of TiN or CrAlN PVD coatings considerably improves the wear resistance of Ti-6Al-4V. Reciprocating ball-on-plate sliding wear measurements were conducted to assess the extent of this improvement. The performance of $\mathrm{CrAlN}$ deposited on pre-nitrided Ti-alloy surpassed all other samples examined in this study. The results presented show that adequate load support must be provided in order for the coating surface to accommodate surface elastic (or plastic) substrate deflections. Enhanced surface modulus and hardness reduced these deflections and increased wear resistance, while also largely reducing the data scatter in material wear loss.

Changes in the coefficient of friction can mainly be attributed to debris generation, which is in turn related to asperity interactions, tribo-oxidation and process-induced surface roughening. The effect of relative humidity on friction has also been investigated. Negligible change has been observed below $50 \%$ RH. Higher humidity levels between 70 and $80 \%$ reduce the coefficient of friction by promoting hydrated oxide tribofilm formation. The frictional behaviour of plasma diffusion (and duplex-diffusion/coating) tribo-systems on Ti-alloy is of particular interest because it significantly affects the wear performance. A rapid progression from negligible to severe wear damage is clearly demarked by an abrupt change in CoF.
Samples which do not demonstrate such abrupt failure not only to survive significantly longer test distances but also exhibit more stable wear rates. It is therefore clear that a more comprehensive testing regime is required to give a true picture of the material behaviour in such systems, particularly since accelerated tests are often meant to simulate product life. More thorough testing procedures and subsequent data analysis, similar to that presented here, should also be accompanied by a better physical understanding of the process mechanisms involved in the particular system being studied.

Maintaining a low $R_{a}$ value may be extremely important, thus post-treatment polishing routes should be investigated but, more ideally, processing parameters should be selected that have little deteriorating effect on the surface finish. Low-pressure enhancedplasma processing techniques such as triode plasma nitriding and electron-beam PAPVD are generally superior in this regard.

\section{Acknowledgements}

The authors gratefully acknowledge financial support for this research work from the UK Technology Strategy Board, under Technology Programme project TP/22076, in collaboration with Tecvac Ltd., NMB-Minebea UK Ltd., and Airbus UK.

\section{References}

[1] B. Bhushan (Ed.), Modern Tribology Handbook, 267-279, CRC Press, New York, 2000, p. 903.

[2] A. Leyland, K.S. Fancey, A. Matthews, Surf. Eng. 7 (3) (1991) 207.

[3] A. Leyland, K.S. Fancey, A.S. James, A. Matthews, Surf. Coat. Technol. 41 (1990) 295.

[4] J.C. Avelar-Batista, E. Spain, J. Housden, A. Matthews, G.G. Fuentes, Surf. Coat. Technol. 200 (5-6) (2005) 1954.

[5] A. Wilson, A. Leyland, A. Matthews, Surf. Coat. Technol. 114 (1999) 70.

[6] J.C. Avelar-Batista, E. Spain, G.G. Fuentes, A. Sola, R. Rodriguez, J. Housden, Surf. Coat. Technol. 201 (7) (2006) 4335.

[7] A. Wilson, A. Matthews, J. Housden, R. Turner, B. Garside, Surf. Coat. Technol. 62 (1993) 600.

[8] S. Ma, K. Xu, W. Jie, Surf. Coat. Technol. 185 (2004) 205.

[9] U. Wiklund, I.M. Hutchings, Wear 251 (2001) 1034

[10] C. Kwietniewski, H. Dong, T. Strohaecker, X.Y. Li, T. Bell, Surf. Coat. Technol. 139 (2001) 284

[11] C. Liu, Q. Bi, A. Matthews, Surf. Coat. Technol. 163-164 (2003) 597.

[12] E. Spain, J.C. Avelar-Batista, M. Letch, J. Housden, B. Lerga, Surf. Coat. Technol. 200 (2005) 1507.

[13] M. Uchida, N. Nihira, A. Mitsuo, K. Toyoda, K. Kubota, T. Aizawa, Surf. Coat. Technol. 177-178 (2004) 627.

[14] M. Okumiya, M. Griepentrog, Surf. Coat. Technol. 112 (1999) 123-128.

[15] Z. Ding, X.T. Zeng, Surf. Coat. Technol. 200 (2005) 1372.

[16] M.J. Donachie Jr., Titanium: A Technical Guide, 2nd edition, ASM International, New York, Materials Park, OH, 2000, p. 8.

[17] A. Molinari, G. Straffelini, B. Tesi, T. Bacci, G. Pradelli, Wear 203-204 (1997) 447.

[18] P.D. Miller, J.W. Holladay, Wear 2 (59) (1958) 133.

[19] P. Psyllaki, G. Kefalonikas, G. Pantazopoulos, S. Antoniou, J. Sideris, Surf. Coat. Technol. 162 (2002) 67

[20] D.H. Hwang, D.E. Kim, S.J. Lee, Wear 225-229 (1999) 427.

[21] N.P. Suh, H.-C. Sin, Wear 69 (1981) 91.

[22] A. Azushima, Y. Tanno, H. Iwata, K. Aoki, Wear 265 (2008) 1017

[23] A. Matthews, D.G. Teer, Thin Solid Films 72 (1980) 541.

[24] B. Podgornik, J. Vizintin, V. Leskovsek, Wear 232 (1999) 231.

[25] M. Rahman, P. Duggan, D.P. Dowling, M.S.J. Hashmi, Surf. Coat. Technol. 201 (2007) 5310.

[26] P.B. Madakson, Wear 87 (1983) 191.

[27] B.G. Mellor (Ed.), Surface Coatings for Protection Against Wear, CRC Press, New York, 2006, p. 8.

[28] K. Holmberg, A. Matthews, Coatings Tribology-Properties, Techniques, and Applications in Surface Engineering, Elsevier Trib. Ser., vol. 28, Elsevier Science, Netherlands, 1994, p. 98.

[29] E. de Wit, L. Froyen, J.P. Celis, Wear 221 (1998) 124.

[30] E. Vacoille, B. Blanpain, Y. Xingpu, J.P. Celis, J.P. Ross, J. Mater. Res. 9 (4) (1993) 992.

[31] R. Rybiak, S. Fouvry, T. Liskiewicz, B. Wendler, Surf. Coat. Technol. 202 (2008) 1753.

[32] E. de Wit, L. Froyen, J.P. Celis, Wear 231 (1999) 116.

[33] J.K. Lancaster, Y.A.-H. Masha, A.G. Atkins, J. Phys. D: Appl. Phys. 25 (1992) 205.

[34] M.G. Gee, Wear 153 (1992) 201 
[35] S.-Y. Yoon, M.-C. Kang, S.-C. Kwon, K.H. Kim, Surf. Coat. Technol. 157 (2002) 144.

[36] T. Liskiewicz, R. Rybiak, S. Fouvry, B. Wendler, J. Eng. Tribol. 220 (J) (2006) 125.

[37] R.S. Magaziner, V.K. Jain, S. Mall, Wear 264 (2008) 1002.

[38] E. Rolinski, Mater. Sci. Eng. A108 (1989) 37.
[39] T.M. Murleedharan, E.I. Meletis, Thin Solid Films 221 (1992) 104.

[40] J.L. Mo, M.H. Zhu, B. Lei, Y.X. Leng, N. Huang, Wear 263 (2007) 1423.

[41] L. Wang, X. Nie, J. Housden, E. Spain, J.C. Jiang, E.I. Meletis, A. Leyland, A Matthews, Surf. Coat. Technol. 203 (2008) 816.

[42] A. Leyland, A. Matthews, Wear 246 (2000) 1. 